\title{
On the Evaluation of Prestress Loss in PRC Beams by Means of Dynamic Techniques
}

\author{
Marco Breccolotti*
}

(Received December 21, 2016, Accepted January 8, 2018)

\begin{abstract}
In the last few decades, prestressing techniques have been used to build very important structures and infrastructures. Since the serviceability and the safety of prestressed reinforced concrete (PRC) elements rely on the effective state of prestressing, development of tools and procedures capable of estimating the effective prestress loss would be very useful. Amongst other techniques, dynamic identification has proved to be an economical, quick and reliable method to evaluate structural integrity. However, the influence of prestressing in the dynamic behavior of PRC elements is not completely clear. In fact, while many references in the literature state that the prestressing force does not affect the frequencies of vibration, almost every experimental test carried out on PRC beams shows an increase in the eigenfrequencies for increasing value of the prestressing force. This paper aims to contribute to the debate, investigating the dynamic behaviour of PRC beams taking into account properties, such as nonlinearity, softening, confinement and micro-cracking of concrete subjected to compression and tension stress states, and the variation of the flexural stiffness of the PRC beam along its length according to bending stress distribution. Non-linear discrete modelling, in combination with system identification and optimization was used to define the dynamic properties of PRC beams, taking into account the effect of prestressing level. The proposed model was applied to four PRC beams with known mechanical and dynamic properties in literature. The influence of the prestressing force on the trend of frequencies of vibration was closely captured for each beam, with errors less than $3 \%$ of the estimated frequencies. The results of this investigation thus indicate that dynamic identification techniques can potentially be used to identify the prestressing force level, and consequently the prestress loss, provided the complete concrete mechanics is taken into account.
\end{abstract}

Keywords: prestressing, prestress loss, dynamic identification, micro-cracking, concrete softening.

$\begin{array}{ll}\text { List of Symbols } \\ \sigma \quad \text { Concrete stress } \\ f_{c} \quad \text { Concrete strength } \\ f_{c c} \quad \text { Confined concrete strength } \\ f_{c o} \quad \text { Unconfined concrete strength } \\ \varepsilon \quad \text { Concrete strain } \\ \varepsilon_{c o} \quad \text { Unconfined concrete peak strain } \\ \varepsilon_{c c} \quad \text { Confined concrete peak strain } \\ E_{c} \quad \text { Concrete elastic modulus } \\ E_{c o} \quad \text { Micro-cracked concrete elastic modulus at the origin } \\ y_{c_{i}} \quad \text { Distance between the i-th concrete fiber and the } \\ \\ y_{s_{j}} \quad \text { concrete centroid } \\ A_{c_{i}} \quad \text { Distance between the j-th steel fiber and the concrete } \\ A_{s_{j}} \quad \text { Area of i-th concrete fiber } \\ \omega & \text { Angular natural frequency and eigenvalue } \\ \bar{d} & \text { Eigenvector }\end{array}$

Department of Civil and Environmental Engineering, Perugia, Italy.

*Corresponding Author; E-mail: brec@unipg.it

Copyright $\odot$ The Author(s) 2018. This article is an open access publication

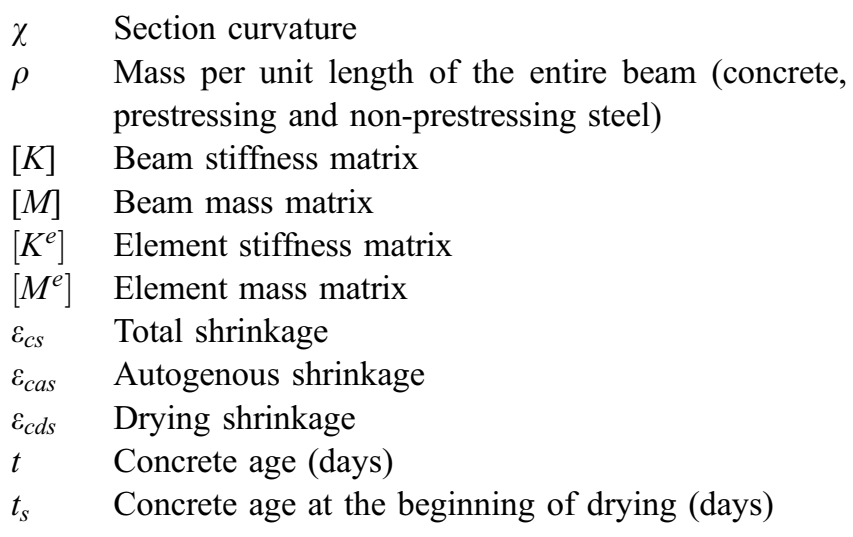

\section{Introduction}

Since the first applications of prestressing to reinforced concrete structures dates back to the first half of the twentieth century by Eugene Freyssinet and Gustave Magnel, prestressing has continuously increased its application to more ambitious and challenging structures. Today prestressing is widely used in many applications, ranging from small elements, such as railway sleepers, to more substantial constructions such as long span bridges, wide thin flat slabs, 
long and light precast flooring and roofing elements for commercial and industrial buildings. Both the serviceability and the safety of prestressed reinforced concrete (PRC) elements rely on the effective state of prestressing (Breccolotti and Materazzi 2015). In fact, the prestressing force is used to control cracks formation, to reduce deflections and to partially counterbalance the effect of dead and live loads. As a consequence, an excessive prestress loss may jeopardize the performance of PRC elements, especially in existing aging structures. It would thus be highly desirable to have tools and procedures capable of estimating the actual loss of prestressing. Besides other emerging methods (Bartoli et al. 2009; Kim et al. 2010; Lan et al. 2012), dynamic identification techniques have proved to be economical, quick and reliable in order to evaluate structural integrity (Salawu 1997). Nevertheless, as far as the influence of prestressing on the dynamic properties of PRC elements is concerned, the debate is still on going. While many experimental investigations indicate that prestressing affects the dynamic properties of PRC beams, there is no definitive evidence to confirm this behaviour from a theoretical point of view.

This paper is set out to investigate the dynamic behaviour of PRC beams, taking into account, as far as possible, the most comprehensive mechanical behaviour, including nonlinearity, softening, confinement and micro-cracking of the concrete subjected to compression and tension stress states and variation of the flexural stiffness of the PRC beam along its length, as per bending stress distribution. At first, experimental investigations and theoretical analysis are reviewed. The next stage focuses on factors that could affect the bending tangent stiffness of PRC sections such as materials nonlinearity, concrete cracking and micro-cracking, concrete confinement and axial and bending stresses acting along the PRC elements. Finally, dynamic identification techniques were applied to the results of several experimental tests found in literature and the main features of concrete mechanics that influence the dynamic behaviour of PRC beams have been identified.

\section{Literature Review}

Research efforts have been devoted to investigate the effect of prestressing on the dynamic behaviour of beams made of different materials since late 1960s. A brief review of the main contributions of this topic is presented herein, including experimental tests and theoretical investigations.

\subsection{Experimental Tests}

James et al. (1964) were among the first to investigate the dynamic response of a prestressed beam in 1964. Although the study was mainly focused on comparison between flexural rigidity of reinforced and prestressed beams as opposed to evaluating the effect of different prestressing levels applied to the same beam, they observed that the modulus of elasticity of prestressed concrete beams should be $20-30 \%$ higher than that of the companion reinforced concrete beams in order to obtain the same dynamic features.
In 1976 Kerr (1976) carried out several experimental tests on a steel cantilever beam with a continuously supported barycentric tendon. Based on the results and theoretical investigations, the author found that the natural frequencies were not affected by the magnitude of the prestressing force.

A few years later, Hop (1991) monitored the dynamic behaviour of several PRC beams made from normal and lightweight concrete. Investigation looked at the effect of prestressing levels on frequency and damping of concrete beams. The author found that applying an increasing prestressing force, acting unevenly on the beam, would increase the frequency of vibration. In several cases, it has been recorded that application of further degrees of prestress increase, would result in drop of frequency of vibration.

Similar experimental results obtained by Saiidi et al. (1994) who tested a PRC beam with a concentric ungrouted strand and prestressing force varying from 0 to 0.5 times the compression strength of the concrete section. Investigations demonstrated an increase in the first eigenfrequency from $11.41 \mathrm{~Hz}$ for the case of null prestressing force, to $15.07 \mathrm{~Hz}$ $(+32.1 \%)$ for maximum value of prestressing.

Miyamoto et al. (2000) tested the dynamic behaviour of prestressed beams, strengthened with external tendons. According to their findings, prestressing forces introduced to external tendons, affect the natural frequency of vibration of the girder. In particular, in the case of slightly eccentric tendon arrangement, the authors found that the natural frequency decreased for the dominance of axial force.

$\mathrm{Lu}$ and Law (2006) tested a $4.0 \mathrm{~m}$ long RC beam with an ungrouted seven-wire straight strand, located at the centroid of the beam cross-section. Two conditions were tested: with and without a prestressing force of $66.7 \mathrm{kN}$. The authors observed that the application of the prestressing force produced an increase in the first three eigenfrequencies in range of $0.4-2.1 \%$.

Xiong and Zhang (2009) tested three externally prestressed, simply supported concrete beams with different paths of the external tendons. The authors observed that the natural frequency of beams increased in the first stage with the increased prestressing force. Inversely, the natural frequency decreased after the cracks produced by the prestressing forces occurred in the beams.

Kim et al. (2010) tested a laboratory-scaled PRC girder for several damage scenarios of prestress loss in the tendon. Starting from a state of no prestress loss, the external prestressing force has been gradually reduced to Zero. During this unloading process, dynamic measurements allowed to identify reductions of the first four eigenfrequencies up to values of $4.0-4.4 \%$ from the initial stage to the final one.

Jang et al. (2010) tested six scaled post-tensioned concrete beams with bonded tendons. By applying a continuously increasing prestressing force from 0 to $523 \mathrm{kN}$, the authors observed a progressive increase of the first eigenfrequency from 7.6 to $8.7 \mathrm{~Hz}(+15.7 \%)$.

Maas et al. (2012) observed that in an undamaged beam subjected to compressive stress by tensioning a central reinforcement with a hydraulic jack, the increase in the first three eigenfrequencies is roughly equal to $1 \%$ for each $\mathrm{MPa}$ 
increase in the concrete compression stress. They also assumed that this stiffness increase was due to the closure of small micro-cracks in the concrete produced by compression stress.

Recently, Noh et al. (2015) carried out experimental tests on 3 PRC beams with different strand configurations. They detected that generally, natural frequency increased as tensile force in the prestressing steel was increased. They also noted that frequencies of vibrations of internally prestressed concrete beams were affected by other parameters, such as tendon profile and boundary conditions.

The results of the most relevant experimental investigations (Saiidi et al. 1994; Kim et al. 2010; Zhang 2007; Jang et al. 2010) are summed up in Figs. 1 and 2. These investigations have been selected from those mentioned above as they are related to tests on reinforced concrete elements and in the interest of data completeness, reported in the source papers. In the graphs, ratios between vibration frequency of prestressed beam $f_{p}$ and that of the non-prestressed beams $f_{0}$ are plotted against the ratios between prestressing force $P$ and the nominal compression strength $N_{u}$ of the concrete cross-section for the first two frequencies of vibration. The ratio between the tendon eccentricity and the height of the beam is also demonstrated. Some general trends can be extracted from these figures. Firstly, it can be stated that for low levels of prestressing force, a prestress increase produces an increase in eigenfrequencies, especially for fundamental frequency of vibration. For higher values of the prestressing force the rate of increase of eigenfrequencies tends to decrease. Furthermore, it can be observed that variations in frequencies of vibrations are higher for smaller values of the prestressing cable eccentricity.

From the abovementioned references it can be claimed that prestressing affects the dynamic properties of PRC beams.

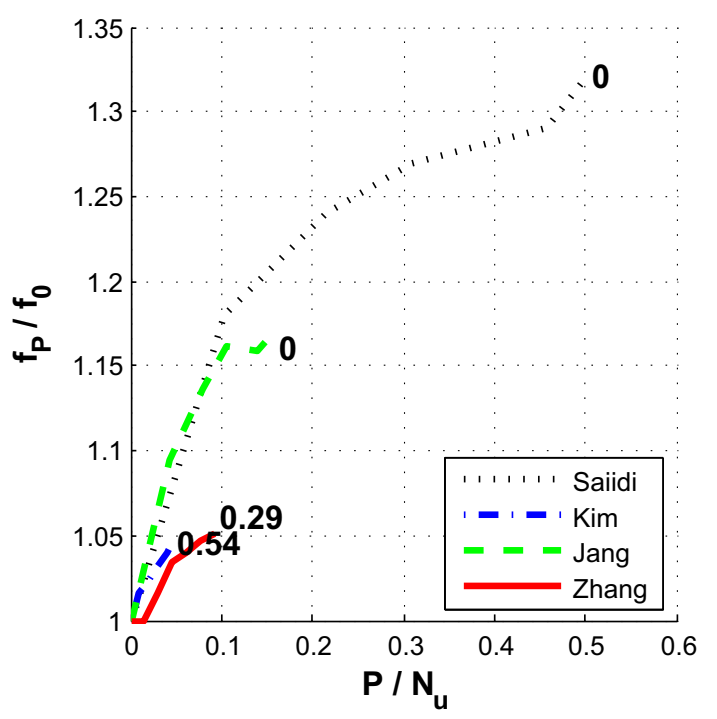

Fig. 1 Effect of the ratio between the prestressing force $P$ and the ultimate compression strength $N_{u}$ on the 1 st frequencies of vibration.

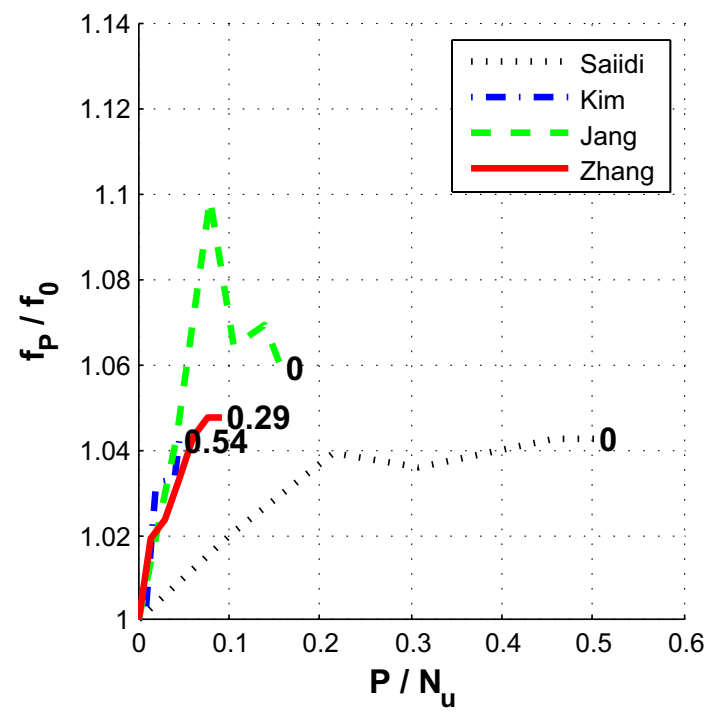

Fig. 2 Effect of the ratio between the prestressing force $P$ and the ultimate compression strength $N_{u}$ on the 2nd frequencies of vibration.

Nevertheless, relevance of these modifications depends on many aspects (concrete cracking, concrete nonlinearity, strands bonding, strands eccentricity,...) that sometimes produce counterbalancing effects making it difficult to identify a clear link between dynamic properties and level of prestressing.

\subsection{Theoretical Investigations}

Several theoretical investigations have been carried out in recent years addressing the influence of prestressing on the dynamic properties of PRC beams.

During the development of a moving force identification method that takes into account the effects of prestressing, Chan and Yung (2000) observed, that the natural frequencies of a prestressed bridge decrease with the increase of the prestress forces due to the compression softening effect.

Kim et al. (2004) developed a non-destructive method to detect prestress-loss in beam type PRC bridges based on measurement of changes in the natural frequencies. Comparison between the experimental results obtained by Saiidi et al. (1994) and the previsions of their model allowed for validation of this method.

From the theoretical point of view, Law and $\mathrm{Lu}$ (2005) analyzed the time-domain response of a prestressed EulerBernoulli beam under external excitation. By comparing the results of numerical simulations with the theoretical findings, the authors were able to identify the prestress force in the time domain by measuring displacements and strains. According to their findings, the frequency of vibrations decreases as prestressing force increases.

Hamed and Frostig (2006) developed a nonlinear analytical model for dynamic behavior of prestressed beams with bonded and unbonded tendons. Based on the derived governing equations authors proved that the magnitude of 
prestressing force does not affect the natural frequencies of bonded or unbonded prestressed beams.

Looking at the abovementioned references it can be observed that, from the theoretical point of view, there is no agreement on the effect of prestressing on dynamic behaviour of PRC beams.

\section{Dynamic Behaviour of PRC Beams}

To assess the effect of the prestressing force on the dynamic behavior of PRC beams, an accurate modelling of concrete mechanical behavior, both in tension and in compression, is necessary. For this purpose, the following aspects have been investigated:

1. Compression softening;

2. Concrete softening under increasing compressive stresses produced by the damaging process inside the material;

3. Concrete hardening under increasing compressive loads due to the confinement effect produced by the transversal and longitudinal steel reinforcements;

4. Concrete early-age cracking due to the restrained shrinkage and thermal deformations.

\subsection{Compression Softening}

Based on existing literature (for instance the work by Hamed and Frostig 2006) it is demonstrated that, assuming linear elasticity, the magnitude of the prestress force does not affect the natural frequencies of PRC beams in both cases of bonded and unbonded strands that undergo the same transversal displacement of concrete sections during vibration. In the case of unbonded straight tendons, concrete element could vibrate without dragging in vibration prestressing tendons. In this case, neglecting small rotations at the beam ends, prestressing force can be considered as an external compression force. Consequently, the natural frequency of simply supported axially compressed beams can be derived from Eq. 1 that includes the compression softening effect:

$$
\omega_{n}^{2}=\left(\frac{n \pi}{L}\right)^{4} \frac{E I}{m}-\left(\frac{n \pi}{L}\right)^{2} \frac{N}{m}
$$

where $n$ is the mode number, $L$ is the beam length, $N$ is the axial compressive force (positive), $m$ is the beam mass per unit length and $E I$ is the uniform flexural stiffness of the beam. Nevertheless, this case seldom occurs in real situations. In fact, in parabolic or draped tendons configurations, the strands are in contact with the ducts and, thus, with the concrete, hence they vibrate together with concrete beams. For straight tendons configurations of pre-tensioned beams, tendons are bonded to the concrete, thus vibrating together with the concrete beam. In straight tendons configurations of post-tensioned beams, strands are generally grouted inside the ducts to reduce the risk of corrosion and to improve the load bearing capacity at ultimate limit state. Also, in this case tendons vibrate together with the concrete beam. Consequently, the compression softening effect rarely occurs in real prestressed structures and will be disregarded in the subsequent analysis.

\subsection{Concrete Softening}

Compression behavior of concrete is markedly non-linear with deformations that increase faster than stresses, even at low stress levels. The basic stress-strain parabola provided by Hognestad (1951) has been one of the first constitutive laws to model this behavior (Fig. 3):

$$
\sigma=f_{c o} \cdot\left[2 \cdot \frac{\varepsilon}{\varepsilon_{c o}}-\left(\frac{\varepsilon}{\varepsilon_{c o}}\right)^{2}\right]
$$

From this graph it can be noted that material tangent stiffness decreases for increasing values of compressive stress. Consequently, it is expected that an increase of the prestressing force in an uncracked PRC section will produce a reduction of tangent flexural stiffness.

\subsection{Confinement}

As pointed out by Vecchio (1992) and by other researchers, concrete lateral expansion influences the behavior of RC elements since the confinement effect generated by the stirrups and by the longitudinal reinforcement that opposes the concrete expansion can result in a significant strength and stiffness enhancement. The lateral deformation is generally small for low values of the axial stresses while it becomes more relevant when the concrete undergoes axial plastic deformation. In PRC beams where compressive stresses and strains affect the entire cross-section this behavior can potentially influence their dynamic properties.

According to several researchers (Park et al. 1982; Fafitis and Shah 1985) the effect of confinement can be disregarded for low confinement pressures thus leaving the ascending branch of the stress-strain curve unchanged. Other authors

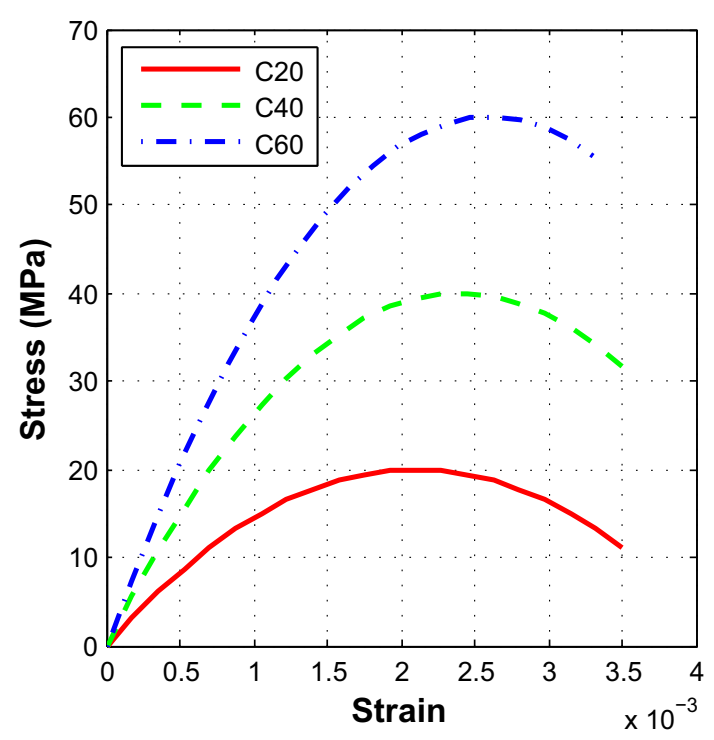

Fig. 3 Nonlinear stress-strain relationships for concretes with different strengths according to Hognestad (1951). 
proposed stress-strain relationships where confinement effect modifies the initial branch as well (Popovics 1973; Madas and Elnashai 1992). Among them, the model proposed by Mander et al. (1988) has been adopted for investigating the influence of confinement on the dynamics of PRC beams. In this case the ascending branch of the constitutive relationship is described by the following equation:

$$
\begin{aligned}
& \sigma=f_{c c} \cdot\left[\frac{r \cdot\left(\frac{\varepsilon_{c}}{\varepsilon_{c c}}\right)}{r-1+\left(\frac{\varepsilon_{c}}{\varepsilon_{c c}}\right)^{r}}\right] \text { for } \quad \varepsilon_{c} \leq \varepsilon_{c c} \\
& r=\frac{E_{c}}{E_{c}-\frac{f_{c c}}{\varepsilon_{c c}}}
\end{aligned}
$$

The ratio between the confined strength $f_{c c}$ and the unconfined strength $f_{c o}$ can be obtained by graphical interpolation (see Mander et al. 1988) as a function of the parameter $k_{e}$ that depends on the geometry of the cross-section and on the reinforcement configuration, and of the lateral confining strengths $f_{l x}$ and $f_{l y}$ in the $x$ and $y$ directions, respectively.

A comparison between the stress-strain relationships for the unconfined and confined concrete is show in Fig. 4. The comparison is relative to a $\mathrm{RC}$ section made with concrete having an unconfined strength $f_{c o}$ of $25 \mathrm{MPa}$. The dimension of the beam cross-section is $0.3 \times 0.3 \mathrm{~m}$, the concrete cover is equal to $20 \mathrm{~mm}$, the longitudinal reinforcement is made up of four rebars with $16 \mathrm{~mm}$ diameter and the stirrups have diameter $6 \mathrm{~mm}$ and are placed with $100 \mathrm{~mm}$ spacing. It can be noted that whilst the main confinement effect takes place during approach to peak strength and in the post-peak region, in the pre-peak region a very small hardening and strengthening effect occurs. It is therefore assumed that the effect of the confinement on the dynamics of PRC beams is negligible and will be neglected in the subsequent analysis.

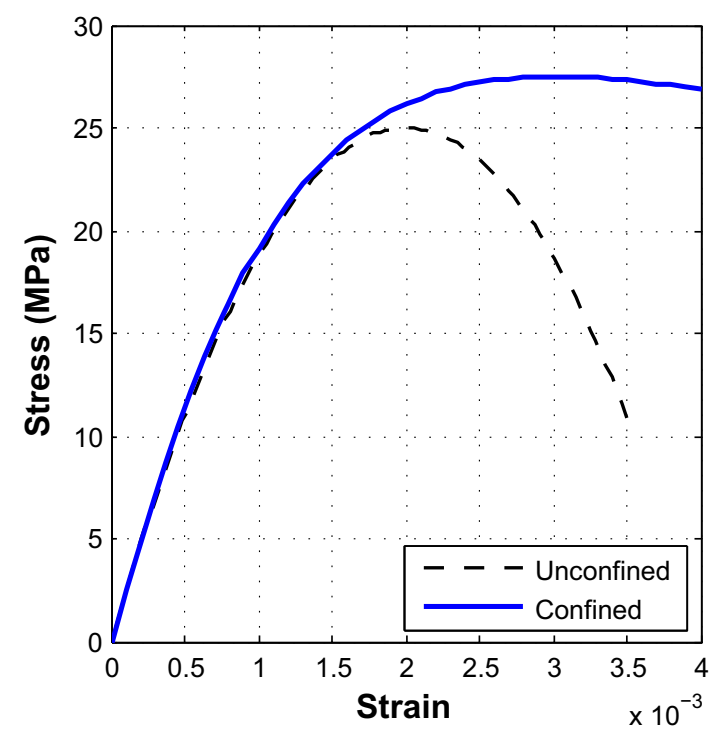

Fig. 4 Comparison between the stress-strain relationships for the unconfined (Hognestad parabola) and confined concrete.

\subsection{Early-Age Cracking}

The issue of early-age cracking gained new attention in the last decades for higher sensitivity on durability aspects of RC structures (Bentur and Kovler 2003; Kovler and Roussel 2011). It can be generally ascribed to the simultaneous occurrence of the following conditions:

1. Volume contraction due to drying and autogenous shrinkage in the cement paste;

2. Volume contraction in cooling phase of the hardened concrete;

3. Presence of restraints that limit the contraction of concrete.

In fact, after casting the concrete mixture, whilst still in fluid state and cannot sustain any loads. Deformations can occur without hindrance. From the moment a supporting structure is formed, hindrance of deformations may cause stresses. Those caused by shrinkage are dependent on development of the stiffness. Whether these stresses lead to cracking depends on the development of strength. In cementitious materials the stiffness generally develops faster in comparison to the strength and, thus, a high crack risk occurs at early-stages. Tensile stresses can also be caused by prevented thermal deformations in cooling phase of hardened concrete. The heat generated by cement hydration in concrete produces a temperature increase and a volume expansion. At the end of the hydration process the temperature decreases and concrete tends to shrink.

Restraints can be caused by other structural elements against which the new element is cast, such as aggregates, formworks or steel reinforcements. The role of reinforcement in formation of cracks is twofold. From one side, it is responsible for the crack formation due to restraint effect, and conversely an increase in the amount of reinforcement can postpone the formation of a through-crack with the formation of several micro-cracks (Sule and van Breugel 2004). In concrete structures higher free shrinkage, higher hydration heat, higher restraint degree, higher elastic modulus and lower creep generally lead to a higher restrained stress and, consequently, to a worse micro-cracking tendency (Gao et al. 2012).

Cracking produced by hindered concrete contraction can be divided in two types (see Fig. 5):

Main cracks that affect large areas of concrete section;

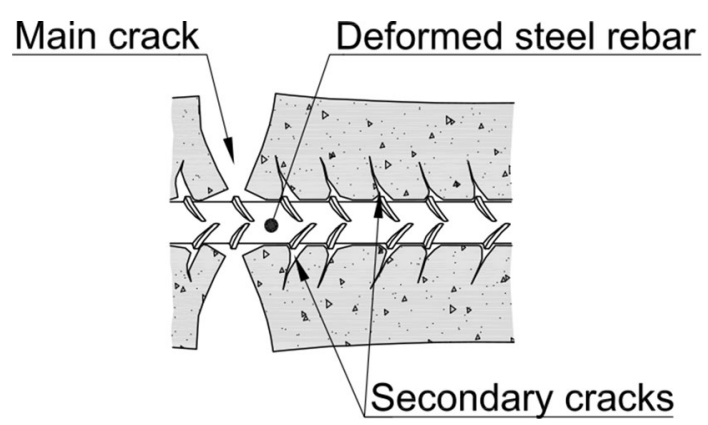

Fig. 5 Main crack and local secondary (micro-cracking) cracks of RC elements (adapted from Goto 1971). 
Local secondary cracks (micro-cracking) that affect the concrete around a single steel rebar.

While the effect of the first type of cracking on the dynamic behavior of RC beams has already been investigated (Breccolotti et al. 2008; Breccolotti and Materazzi 2008), that of the second type is not easily predictable and no relevant references have been found in literature. Nevertheless, some indications have been found on the effect of shrinkage induced micro-cracking on static behavior of RC beams. Tanimura et al. (2003), for instance, found that the use of expansive additive and shrinkage reducing agent produced an increase of flexural cracking load and a reduction of deflection for the same load condition, thus indicating an increase of flexural stiffness of the RC beam. Kaklauskas et al. (2009) investigated the influence of shrinkage on stress-strain state of RC members using test data reported in literature. The results of their investigation demonstrated that shrinkage might reduce the cracking resistance and the stiffness of RC members significantly. It is, therefore, conceivable that shrinkage induced microcracking could also affect the dynamic behavior of PRC beams.

In order to evaluate this influence, a smeared microcracking will be assumed in subsequent analysis. It will be modelled by means of a suitable modification to the original concrete stress-strain curve shown in Fig. 6. This modification is composed of a translation $\varepsilon_{s h}$ of the original constitutive relationship in the direction of higher compressive strains, a reduction of tensile strength and a connecting stretch between translated compression stress-strain curve and reduced tensile strength expressed by means of an exponential law that depends on the exponent $a$.

The mathematical formulation of this behavior is expressed by Eq. 5 for the compression and the tensile stresses, respectively:

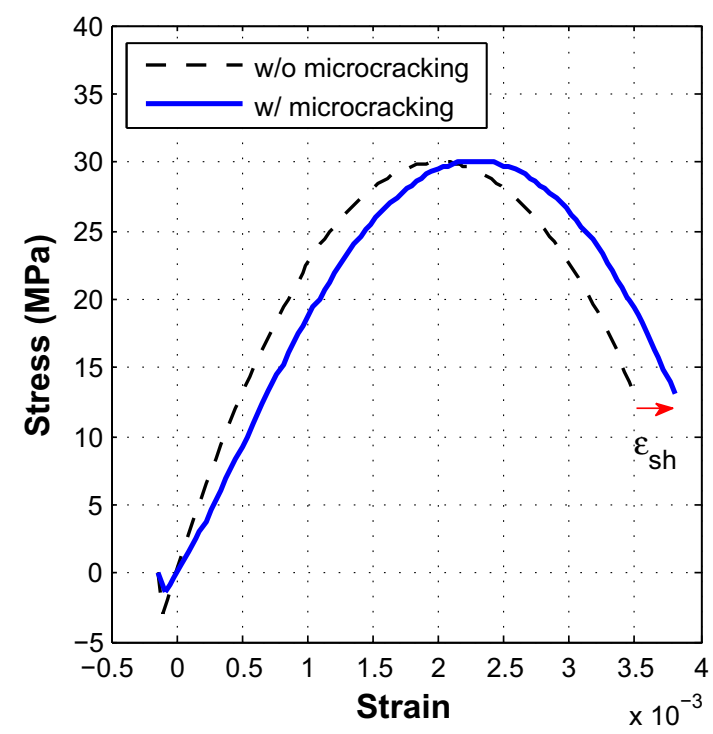

Fig. 6 Stress-strain relationships for the concrete in compression and in tension with (solid curve) and without (dashed curve) micro-cracking.

$$
\sigma(\varepsilon)=\left\{\begin{array}{c}
f_{c o} \cdot\left\{2 \cdot \frac{\varepsilon-\varepsilon_{s h}}{\varepsilon_{c o}}-\left(\frac{\varepsilon-\varepsilon_{s h}}{\varepsilon_{c o}}\right)^{2}+\left[2 \cdot \frac{\varepsilon_{s h}}{\varepsilon_{c o}}+\left(\frac{\varepsilon_{s h}}{\varepsilon_{c o}}\right)^{2}\right] \cdot e^{-a \cdot \varepsilon}\right\} \text { for } \varepsilon \geq 0 \\
E_{c o} \cdot \varepsilon \text { for } \varepsilon<0
\end{array}\right.
$$

where the elastic modulus $E_{c o}$ has been set equal to the concrete modulus for compressive stresses at origin to ensure continuity in the behaviour from compressive to tensile stresses. The value of $E_{c o}$ (Eq. 6) has thus been calculated as the value assumed by the first derivative of Eq. 5 for $\varepsilon \geq 0$ at origin:

$$
E_{c o}=\left.\frac{\partial \sigma}{\partial \varepsilon}\right|_{\varepsilon=0}=f_{c o} \cdot\left[\frac{2}{\varepsilon_{c o}}+2 \frac{\varepsilon_{s h}}{\varepsilon_{c o}^{2}}-a \cdot\left(2 \frac{\varepsilon_{s h}}{\varepsilon_{c o}}+\left(\frac{\varepsilon_{s h}}{\varepsilon_{c o}}\right)^{2}\right)\right]
$$

This general behaviour would allow for initial lower concrete stiffness in compression up to the closure of internal micro-cracking and reduced tensile strength of microcracked concrete to be taken into account.

\section{Flexural Stiffness of PRC Beams}

The flexural behavior of RC beam, with and without prestressing action has been evaluated, considering the features listed in the previous paragraph through a discrete approach. The beam was firstly discretized in the longitudinal direction in a suitable number of finite elements. The dimension of the element has been chosen in order to properly model the discrete location of the main cracks, if they occur. To this end, the element dimension in the longitudinal direction has been set to one third of the distance between two consecutive cracks in the stabilized cracking stage (fib International Federation for Structural Concrete, Model code 2010). The flexural and axial stiffness of these elements have been calculated through a fiber modeling approach (Taucer et al. 1991) dividing each cross-section into finite areas (each fiber characterized by constant stress and strain). Constitutive relationships have been defined in terms of stress-strain relations for every fiber. Hognestad parabola with the proposed modification to take into account micro-cracking has been used for the concrete. Where the original Hognestad law is parabolic only in the pre-peak branch and it is linear in post-peak, the parabolic stressstrain relationship has been used for both the ascending and the descending branches. This assumption did not introduce any inaccuracies in analysis for the level of compressive stresses involved in the case studies that are always smaller than the concrete peak strength. Classical elastic - perfectly plastic stress-strain law is used for reinforcing steel while the power formula proposed by Devalapura and Tadros (1992) was used for prestressing steel:

$$
\sigma=\varepsilon \cdot\left[A+\frac{B}{\left\{1+(C \cdot \varepsilon)^{D}\right\}^{1 / D}}\right]
$$


where $A, B, C$ and $D$ are suitable constants that depend on the type of low-relaxation prestressing strands. The two constitutive laws are shown in Fig. 7.

The classic assumption of Bernoulli (plane cross-sections perpendicular to the axis of the beam before bending remain plane and perpendicular to the bent axis of the beam after bending) has been used to calculate the strains distribution inside the beam cross-section.

The construction of relationship between bending moment $M$ and the curvature $\chi$ was accomplished for each value of the axial force $N$ (which is equal to the prestressing force) by integrating the stresses distribution over the beam cross section:

$$
\begin{aligned}
& N=\sum_{i=1}^{n_{c}} A_{c_{i}} \cdot \sigma\left(\varepsilon_{c_{i}}\right)+\sum_{j=1}^{n_{s}} A_{s_{j}} \cdot \sigma\left(\varepsilon_{s_{j}}\right) \\
& M=\sum_{i=1}^{n_{c}} A_{c_{i}} \cdot \sigma\left(\varepsilon_{c_{i}}\right) \cdot y_{c_{i}}+\sum_{j=1}^{n_{s}} A_{s_{j}} \cdot \sigma\left(\varepsilon_{s_{j}}\right) \cdot y_{s_{j}}
\end{aligned}
$$

with $\varepsilon_{c_{i}}=\chi \cdot y_{c_{i}}$ and $\varepsilon_{s_{i}}=\chi \cdot y_{s_{i}}$.

Several examples of moment-curvature relationships for the same cross-section but with different values of prestressing force are shown in Fig. 8. It is evident that prestressing action not only alters the limits of the uncracked stage but also slightly changes its bending stiffness. For each value of axial load $N_{i}$ and each value of bending moment $M_{i}$ the tangent flexural stiffness $E I_{i}$ of the beam can be calculated as:

$$
E I_{i}\left(N_{i}, M_{i}\right)=\frac{d M(\chi)}{d \chi}
$$

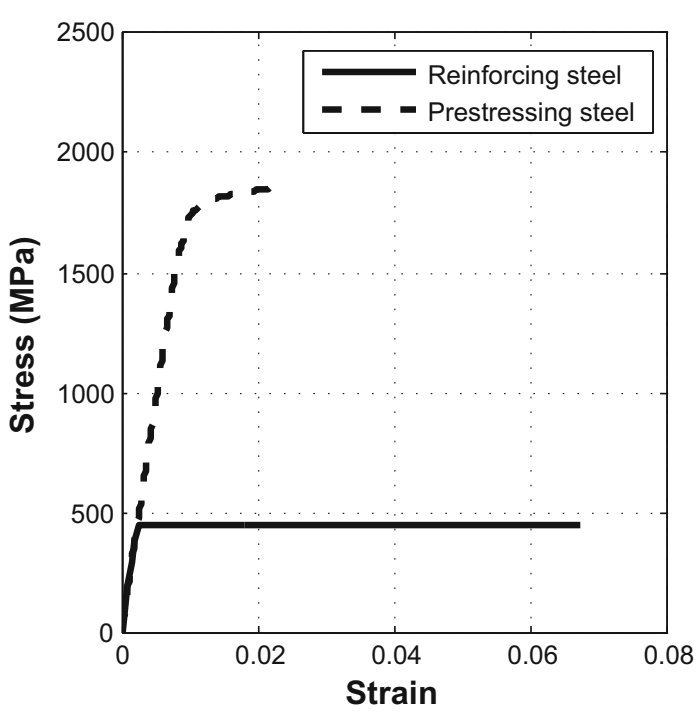

Fig. 7 Stress-strain relationships for reinforcing and prestressing steels.

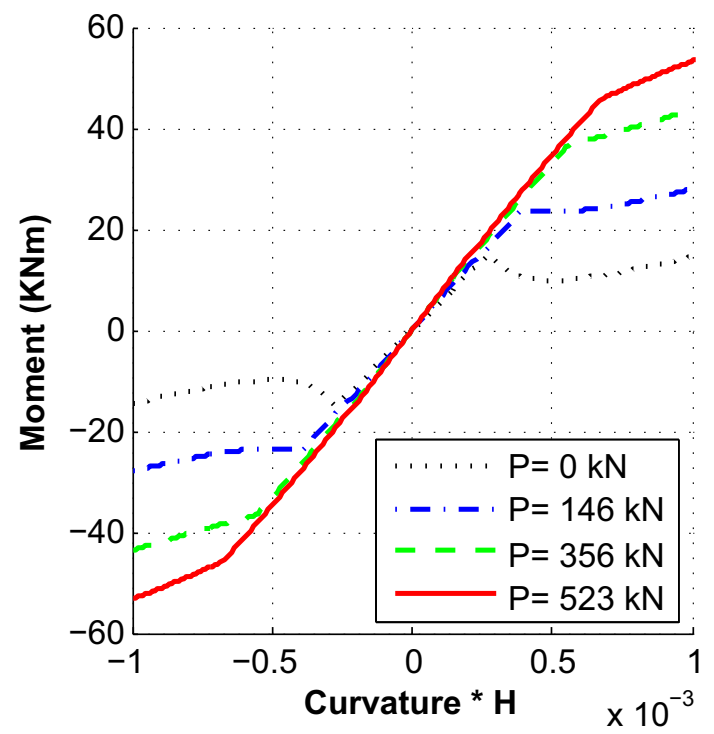

Fig. 8 Moment-curvature relationships for different values of the prestressing force $P$.

\section{Numerical Modeling of the Dynamics of PRC Beams}

Assuming a negligible influence of structural damping, the dynamic behavior of PRC beams has been studied, solving the classical eigenvalues problem:

$$
\left([K]-\omega^{2}[M]\right)\{\bar{d}\}=0
$$

where the stiffness $[K]$ and mass $[M]$ matrices of the entire beam has been assembled from element stiffness $\left[K_{i}^{e}\right]$ and consistent mass $\left[M^{e}\right]$ matrices:

$$
\begin{aligned}
& {\left[K_{i}^{e}\right]=\frac{E I_{i}}{l^{3}} \cdot\left[\begin{array}{cccc}
12 & 6 l & -12 & 6 l \\
6 l & 4 l^{2} & -6 l & 2 l^{2} \\
-12 & -6 l & 12 & -6 l \\
6 l & 2 l^{2} & -6 l & 4 l^{2}
\end{array}\right]} \\
& {\left[M^{e}\right]=\frac{\rho A l}{420} \cdot\left[\begin{array}{cccc}
156 & 22 l & 54 & -13 l \\
22 l & 4 l^{2} & 13 l & -3 l^{2} \\
54 & 13 l & 156 & -22 l \\
-13 l & -3 l^{2} & -22 l & 4 l^{2}
\end{array}\right]}
\end{aligned}
$$

Mass per unit length $\rho$ comes from the concrete, non-prestressing and prestressing steel. It must be noted that the mass of prestressing steel is considered also in the case of null prestressing force since prestressing strands are not removed from the beam, but simply they are non-tighten. The flexural stiffnesses $E I_{i}$ of Eq. 12 of each element have been obtained from the moment-curvature relationships recalled in par. 4 and shown in Fig. 8 as tangential stiffness, measured on the curve for the specific prestressing force and for bending moment produced by external loads and by prestressing force on the specific element (Eq. 10). The numerical procedure to calculate the stiffness $[K]$ and mass $[M]$ matrices of the PRC beam is summed up in the flowchart of Fig. 9. 


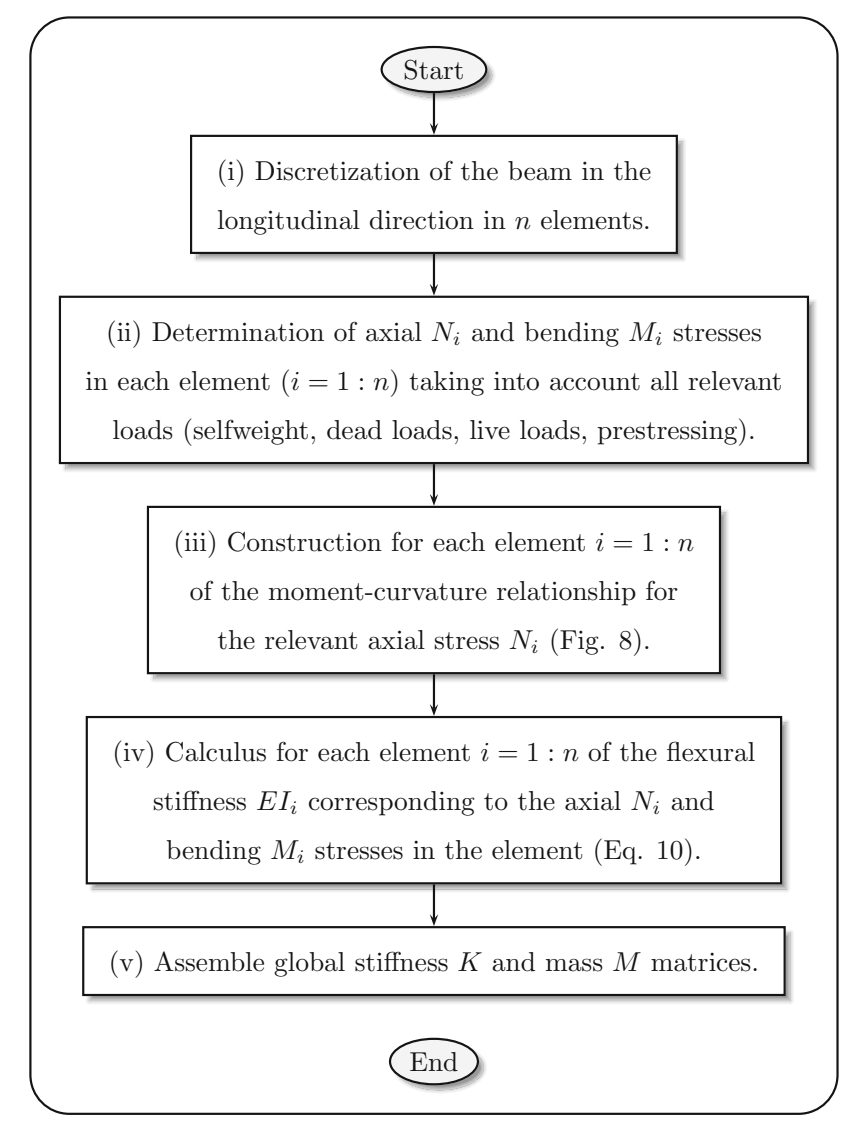

Fig. 9 Flowchart to calculate global stiffness $K$ and mass $M$ matrices.

\section{Identification of the Unknown Parameters}

The proposed numerical modeling of dynamic behavior of PRC beams has been applied to several experimental investigations, results of which are available in literature (Saiidi et al. 1994; Kim et al. 2010; Zhang 2007; Jang et al. 2010) in order to check correctness of assumptions made in numerical modeling. Nevertheless, direct application of the proposed method is not viable since the parameters $\varepsilon_{s h}$ and $a$ that describe the correction of concrete stress-strain relationship (which takes into account the concrete microcracking) are unknown. Furthermore, even if the nominal concrete strength was evaluated by means of conventional tests on concrete samples, the effective concrete strengths of tested beams may differ from those of small size samples. Nominal concrete strength obtained by the 28 days compressive tests on small dimension samples can in fact, be different from that of the real structure. For instance, it can be smaller than that of tested PRC beam for hardening duration of concrete belonging to the beam at the time when dynamic tests are carried out in excess of 28 days. Conversely, it can be greater than that of the tested PRC beam, where inadequate curing and compaction procedures were applied to the PRC element, as opposed to the standard procedure applied to small size concrete samples (CEN European Committee for Standardization, EN 13791 2007). For this reason, concrete strength $f_{c}$ has been considered an unknown parameter too.
The problem has been solved by considering concrete mechanics described by Eqs. 5 and 6. Tangent stiffness of each beam elements has been calculated as per procedure described in Sect. 4. The eigenvalues problem represented by Eq. 11 has been thus expressed as a function of parameters $f_{c}, \varepsilon_{s h}$ and $a$. Identification of these unknown parameters has been carried out essentially as an optimization process by minimizing the values of error function expressed in terms of unknown parameters and the first eigenfrequencies of experimental tests $f_{1, \exp , i}$ and, numerical simulations $f_{1, \text { num }, i}$. The optimization problem can consequently be formulated as follow:

$$
\min _{\left(f_{c}, \varepsilon_{s h}, a\right)} \sum_{i=1}^{n}\left(f_{1, \exp , i}-f_{1, \text { num }, i}\right)^{2}
$$

with constraints: $0.6 f_{c, \text { nom }} \leq f_{c} \leq 1.4 f_{c, \text { nom }}, 10^{-6} \leq \varepsilon_{s h} \leq 10^{-4}$ and $10^{3} \leq a \leq 10^{5}$ and where $n$ is the number of prestress load values applied in each experimental test. The choice of using only 1 st frequencies of vibration in the optimization process was based on data found in references and on previous investigations carried out by the author (Materazzi et al. 2009). It is in fact generally true that the effect of prestressing in modifying frequencies of vibration is much more relevant in the 1st mode rather than the higher ones, as visible by comparing Figs. 1 and 2. Data about 2nd frequencies of vibration were initially added in the optimization process but the error achieved in this case turned out to be higher than that obtained with only 1 st one, probably due to lower accuracy in evaluating the higher modes of vibration.

Optimization problem was solved by means of the genetic algorithm toolbox of Matlab (2007a). Populations of 100 terns of the unknown parameters $f_{c}, \varepsilon_{s h}$ and $a$ were generated in each step up to a maximum of 100 generations. An example of convergence error for this optimization process is shown in Fig. 10 for the case of Saiidi et al. experimental tests. It can be noted that the convergence error is reduced to an acceptable value, starting from a few tens of generations.

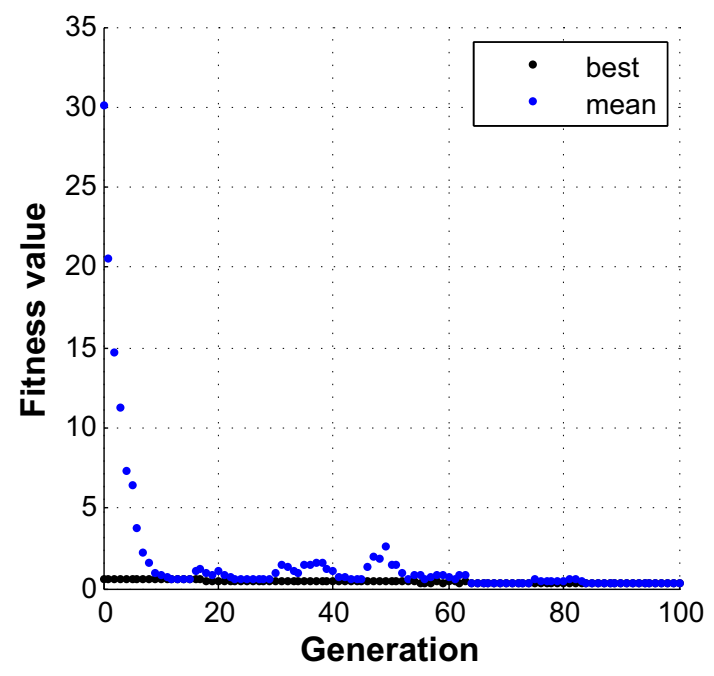

Fig. 10 Error convergence in the GA optimization for Saiidi et al. (1994) PRC beam. 
Similar results have been also obtained for other experimental tests. The results of identification process for the above mentioned experimental investigations are presented and discussed in the next paragraphs.

\subsection{Comparison with Tests by Saiidi et al.}

In 1994 Saiidi et al. (1994) tested a prestressed beam with clear $3.66 \mathrm{~m}$ length between supports, a cross section of $0.102 \mathrm{~m}$ wide and $0.127 \mathrm{~m}$ high. Prestressing was achieved by means of a $0.5 \mathrm{in}$. strand, placed centrally in a duct that remained ungrouted. At one end of the beam a load cell was placed between the beam and the dead anchorage. At the other end, a hydraulic jack applied prestressing forces to the strand, as per Table 1. For each value of prestressing force, free-vibration tests were conducted, measuring the eigenfrequencies listed in the same table.

Dynamic identification procedure identified the unknown parameters listed in Table 5. Accuracy on the evaluation of the unknown parameters can be argued by looking at Fig. 10 where the convergence of fitness value (error) calculated by means of objective function (Eq. 14) for investigated generations are highlighted. Distributions of flexural stiffness corresponding to the identified unknown parameters are shown in Fig. 11. An abrupt stiffness reduction at midspan for the curve corresponding to non-prestressed beam can be noted amongst them. This reduction is caused by formation of a flexural crack in the concrete. Formation of this crack was also noted by the authors who highlighted the development of a small crack at the beams midspan under its own weight. The effect of midspan crack can be identified by looking at the way the first two eigenfrequencies increase at the beginning of prestressing. 1st frequency of vibration increases by $18 \%$ from 11.41 to $13.47 \mathrm{~Hz}$, while the 2nd increases by only $2 \%$ from 43.99 to $44.89 \mathrm{~Hz}$. This behavior is caused by the midspan crack which forms in non-prestressed case and closes after prestressing. By considering the first two mode shapes, it can be noted that closure of midspan crack, affects the 1st mode of vibration while leaving the 2nd one practically unaffected for the point of contraflexure at midspan in the second flexural mode shape. Presence of the crack does not become more visible when prestressing force is applied to the beam. It can, thus, be assumed that prestressing force is able to close the crack during dynamic tests.

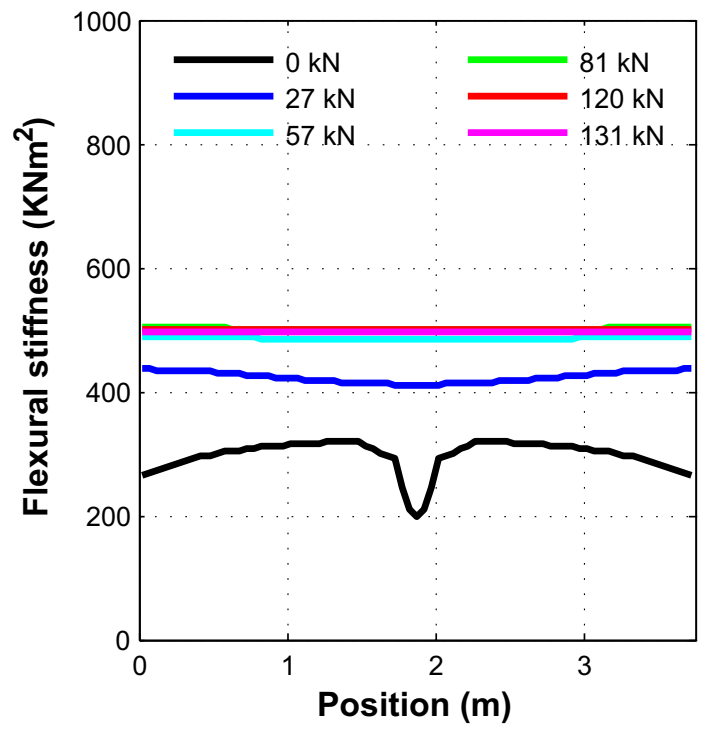

Fig. 11 Distribution of the flexural stiffness along the beam tested by Saiidi et al. (1994) for different values of prestressing force $P$.

Comparison between experimental and numerical fundamental eigenfrequencies for different level of prestressing is show in Fig. 12. In this figure, relative errors (\%) between experimental and numerical frequencies are reported. A good correlation between experimental and numerical values can be observed. From this figure, it can be argued that for very high prestressing force concrete softening becomes predominant with very small increments of the 1st frequency of vibration.

\subsection{Comparison with Tests by Kim et al.}

In $2007 \mathrm{Kim}$ et al. (2010) tested a T-shaped girder having an overall height of $0.6 \mathrm{~m}$ and a clear length of $6.0 \mathrm{~m}$ simply supported by thin rubber pads. A 0.6 in. straight strand was used as an ungrouted, prestressing tendon. Starting from an initial value of $117.6 \mathrm{kN}$, prestressing force was progressively reduced down to a null, in 5 discrete steps. For each prestressing value, the first eigenfrequencies were extracted with a frequency-domain decomposition technique from the free response of the beam after an impact excitation. Values of prestressing forces and corresponding frequencies of vibration are shown in Table 2. Also, in this case it can be

Table 1 Prestressing force and corresponding measured 1st and 2nd frequencies by Saiidi et al. (1994).

\begin{tabular}{c|c|c}
\hline Prestressing force & 1st frequency & \multicolumn{2}{|c}{ 2nd frequency } \\
\hline$(\mathrm{kN})$ & $(\mathrm{Hz})$ & 43.99 \\
\hline 0 & 11.41 & 44.89 \\
\hline 26.7 & 13.47 & 45.71 \\
\hline 56.6 & 14.15 & 45.57 \\
\hline 80.9 & 14.49 & 45.86 \\
\hline 120.1 & 14.72 & 45.87 \\
\hline
\end{tabular}




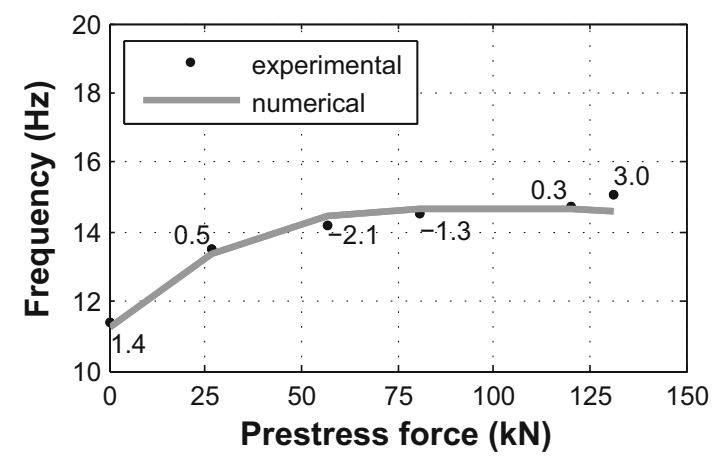

Fig. 12 Comparison between the 1st experimental frequencies of vibration obtained by Saiidi et al. (1994) and the corresponding values obtained numerically. Also shown, are the corresponding relative errors (\%) for each prestressing value.

noticed that the natural frequency of vibration increases for higher values of prestressing force.

Dynamic behavior of the beam was simulated with the methodology established in previous paragraphs and unknown parameters have been determined by minimizing the objective function. The identified unknown parameters are listed in Table 5. Distributions of flexural stiffness for each value of prestressing force are shown in Fig. 13. The hardening effect produced by prestressing force on the elements flexural stiffnesses is visibly evident. In Fig. 14 the comparison between the first experimental frequencies of vibration and the corresponding values obtained by the numerical simulation is demonstrated. It can be clearly observed that in this case that the 1st frequency of vibration continuously increases as the value of prestressing force increases. This behavior can be attributed to the small value of maximum prestressing force $P$ in comparison to the ultimate compression strength $N_{u}$ of the beam cross section $\left(P / N_{u}=0.04\right)$. Nevertheless it must be pointed out that in this case, relative errors up to $1.5 \%$ (for the maximum prestress force) have been obtained between frequencies of vibration evaluated with the proposed methodology and the experimental ones. These errors can probably be ascribed to some missing information (such as the amount of non-prestressed reinforcement) not available in the reference source.

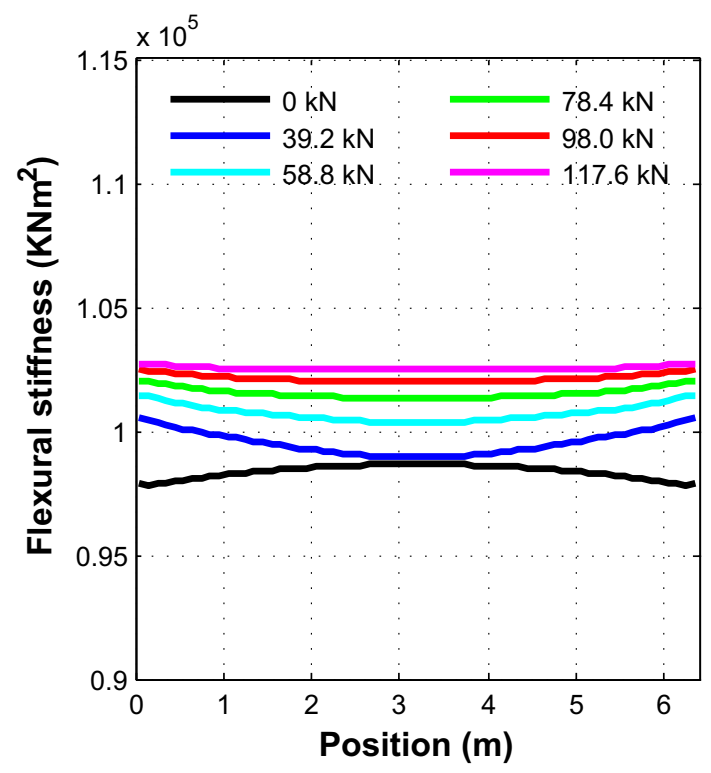

Fig. 13 Distribution of the flexural stiffness along the beam tested by Kim et al. (2010) for different values of prestressing force $P$.

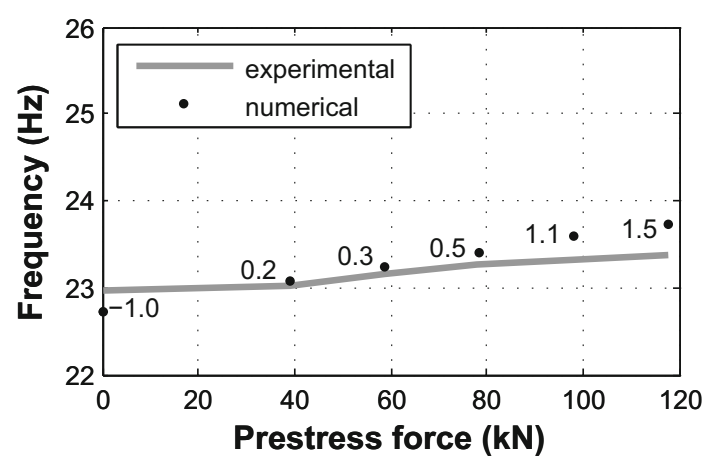

Fig. 14 Comparison between the 1st experimental frequencies of vibration obtained by Kim et al. (2010) and the corresponding values obtained numerically. Also shown are the corresponding relative errors (\%) for each prestressing value.

\subsection{Comparison with Tests by Zhang and $\mathrm{Li}$}

Zhang and Li (2007) tested a rectangular concrete beam with a linear unbonded tendon. The beam was simply supported with a cross section of $0.12 \times 0.24 \mathrm{~m}$ with a total length of $3.9 \mathrm{~m}$ and a distance between the supports of 3.7

Table 2 Prestressing force and corresponding measured 1st and 2nd natural frequencies by Kim et al. (2010).

\begin{tabular}{c|c|c}
\hline Prestressing force & 1st frequency & 2nd frequency \\
\hline$(\mathrm{kN})$ & $(\mathrm{Hz})$ & 98.42 \\
\hline 0 & 22.73 & 98.73 \\
\hline 39.2 & 23.08 & 101.39 \\
\hline 58.8 & 23.23 & 101.65 \\
\hline 78.4 & 23.39 & 101.70 \\
\hline 98.0 & 23.60 & 102.54 \\
\hline 117.6 & 23.72 & \\
\hline
\end{tabular}


Table 3 Prestressing force and corresponding measured 1st and 2nd frequencies by Zhang and Li (2007).

\begin{tabular}{c|c|c}
\hline Prestressing force & 1st frequency & 2nd frequency \\
\hline$(\mathrm{kN})$ & $(\mathrm{Hz})$ & 100.71 \\
\hline 0 & 28.36 & 102.67 \\
\hline 20 & 28.36 & 103.09 \\
\hline 40 & 28.83 & 104.07 \\
\hline 60 & 29.32 & 105.05 \\
\hline 80 & 29.48 & 105.50 \\
\hline 100 & 29.69 & 105.53 \\
\hline 120 & 29.80 & \\
\hline
\end{tabular}

$\mathrm{m}$. The 28-day cube crushing strength of the concrete was 45.2 MPa. Prestressing steel was made with an eccentric 0.6 in. tendon while the reinforcing steel was made with 2 bars of $8 \mathrm{~mm}$ diameter in the upper part of the beam and 2 bars of $12 \mathrm{~mm}$ diameter in the lower part of the beam. Stirrups with diameter of $6 \mathrm{~mm}$ were placed with $150 \mathrm{~mm}$ spacing along the beam. Dynamic tests performed with a DH5938 vibration analyzer and a sampling frequency of $1000 \mathrm{~Hz}$ were repeated with increasing values of applied prestressing force. The measured values of the 1 st and 2 nd eigenfrequencies, shown in Table 3 , increased for increasing values of prestressing force.

Dynamic identification procedure allowed for determination of unknown parameters listed in Table 5. Distributions of flexural stiffness for each value of prestressing force are shown in Fig. 15. Even in this case, it is possible to see the initial hardening effect produced by prestressing force in the element flexural stiffnesses with the 1st frequency of vibration that increases as the value of prestressing force increases (Fig. 16). Conversely, for higher prestressing force, concrete softening starts playing a relevant role with very small increments of the 1 st frequency of vibration.

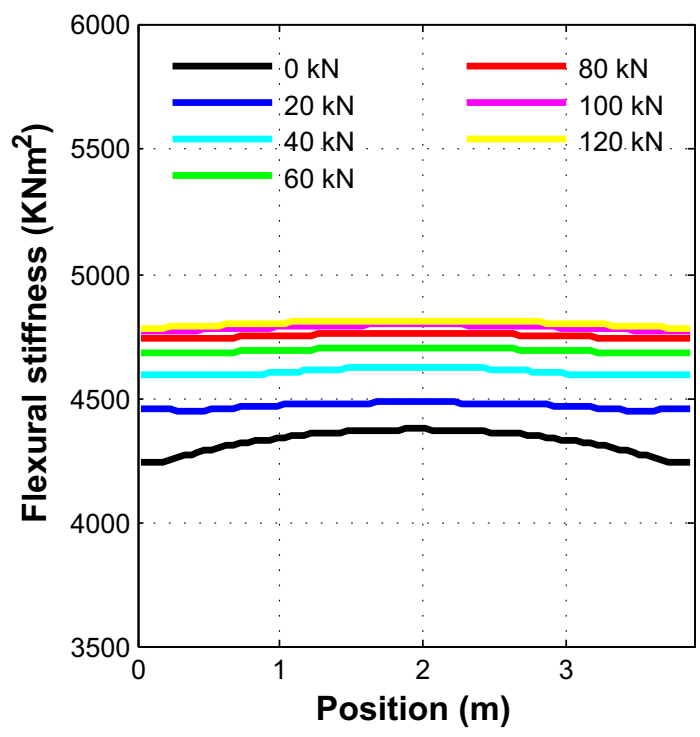

Fig. 15 Distribution of the flexural stiffness along the beam tested by Zhang and Li (2007) for different values of prestressing force $P$.

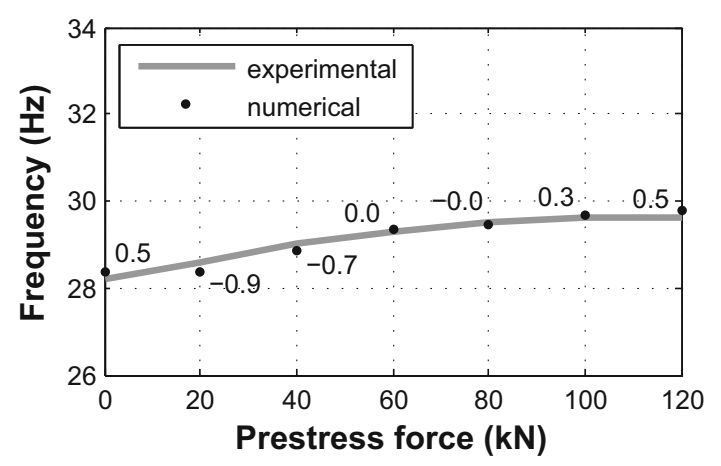

Fig. 16 Comparison between the 1st experimental frequencies of vibration obtained by Zhang and Li (2007) and the corresponding values obtained numerically. Also shown are the corresponding relative errors (\%) for each prestressing value.

\subsection{Comparison with Tests by Jang et al.}

In 2010, Jang et al. (2010) tested a total of six equal scalemodel prestressed beams with bonded strands, each of them having different values of prestressing force. The beams were $8.0 \mathrm{~m}$ long with a clear length between the supports of $7.4 \mathrm{~m}$. Cross section was rectangular with dimension of $0.3 \times 0.3 \mathrm{~m}$. Nominal concrete compressive strength of the tested beams was $35.0 \mathrm{MPa}$. Four rebars with $16 \mathrm{~mm}$ diameter were used for longitudinal reinforcement and 10 $\mathrm{mm}$ diameter stirrups were placed with spacing of 100 and $150 \mathrm{~mm}$. Three $0.6 \mathrm{in}$. strands placed centrally, were used to apply six different prestress force values. Experimental modal tests with impact hammer and Multi-Input MultiOutput sweep tests were used to extract the eigenfrequencies from acceleration time histories, recorded at several points of the prestressed beams by piezo-electric sensors. The results observed in dynamic tests and summed up in Table 4 show that as prestress force increases, natural frequencies also increase.

The proposed minimization procedure allowed to identify unknown parameters listed in Table 5 and the bending stiffness distributions shown in Fig. 17. It can be noted that dynamic identification requires a sudden decrease in flexural stiffness of the beam at midspan for the load case with null prestressing force. Also in this case, the stiffness decrease could be associated to concrete cracking. In places where 
Table 4 Prestressing force and corresponding measured 1st and 2nd frequencies by Jang et al. (2010).

\begin{tabular}{c|c|c}
\hline Prestressing force & 1st frequency & \multicolumn{2}{c}{ 2nd frequency } \\
\hline$(\mathrm{kN})$ & $(\mathrm{Hz})$ & 28.18 \\
\hline 0 & 7.51 & 29.40 \\
\hline 146 & 8.22 & 30.98 \\
\hline 264 & 8.54 & 30.00 \\
\hline 356 & 8.72 & 30.13 \\
\hline 465 & 8.70 & 29.85 \\
\hline 523 & 8.79 & 2 \\
\hline
\end{tabular}

Table 5 Nominal concrete strengths and identified unknown parameters.

\begin{tabular}{c|c|c|c|c}
\hline Experimental tests & $f_{c, 28}$ & $f_{c, \text { iden }}$ & $\varepsilon_{s h}$ & $a$ \\
\hline \hline Saiidi et al. (1994) & $(\mathrm{MPa})$ & $(\mathrm{MPa})$ & $(\%)$ & 0.0911 \\
\hline Kim et al. (2010) & 20.3 & 27.8 & 0.0551 & 5716 \\
\hline Zhang and Li (2007) & 23.6 & 24.3 & 0.0698 & 5015 \\
\hline Jang et al. (2010) & $37.5^{\mathrm{a}}$ & 43.1 & 0.0692 & 6774 \\
\hline
\end{tabular}

a28-day cube strength equal to $45.2 \mathrm{MPa}$.

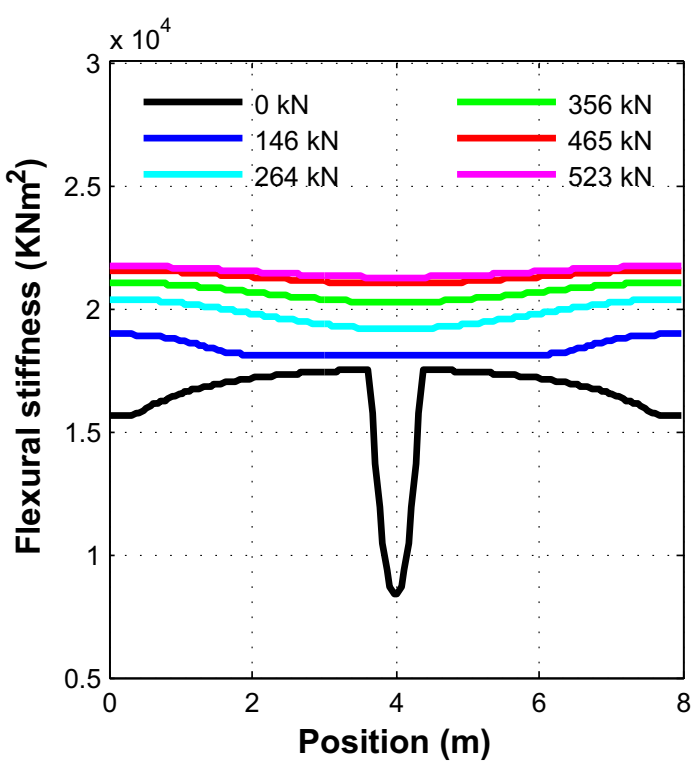

Fig. 17 Distribution of the flexural stiffness along the beam tested by Jang et al. (2010) for different values of the prestressing force $P$.

cracking was not identified in the report of the experimental tests, stress calculations have verified that concrete area of $0.3 \times 0.3 \mathrm{~m}$ section beam on a clear length of $7.4 \mathrm{~m}$ undergoes tensile stresses higher than its tensile strength due to its own weight. In fact, under the self-weight, the midspan section is subjected to a flexural moment of $15.3 \mathrm{kNm}$ that would produce a maximum tensile stress on the concrete equal to $3.4 \mathrm{MPa}$. This value is greater than the mean tensile strength $f_{c t m}$ equal to $3.2 \mathrm{MPa}$ for a concrete that has a compressive strength of $35.2 \mathrm{MPa}$. It can be reasonably assumed that the presence of a crack contributes to the reduction of flexural stiffness. Comparison between

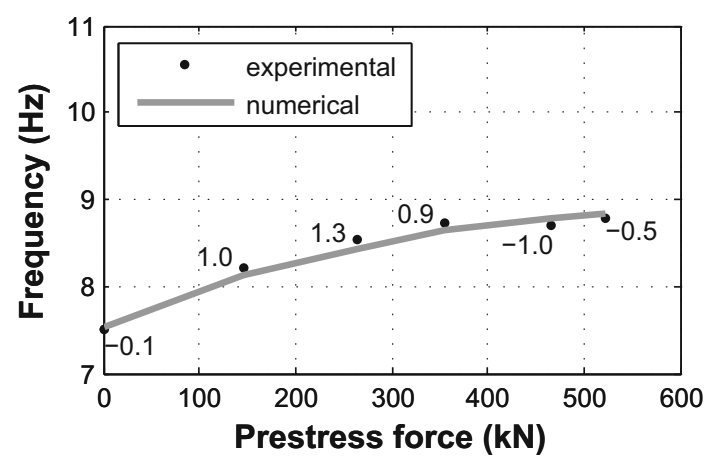

Fig. 18 Comparison between the 1st experimental frequencies of vibration obtained by Jang et al. (2010) and the corresponding values obtained numerically. Also shown are the corresponding relative errors (\%) for each prestressing value.

experimental and numerical fundamental eigenfrequencies for different levels of prestressing is show in Fig. 18. A good agreement between experimental and numerical values and an overall behaviour similar to that noticed for the tests conducted by Zhang and Li can be observed.

\section{Comments to the Results of the Identification Procedure}

Some comments can be made on the results obtained by dynamic identification in terms of unknown parameters $f_{c}$, $\varepsilon_{s h}$ and $a$. The corresponding stress-strain relationships were normalized with respect to the nominal value of concrete strength in each test and shown in Fig. 19 together with a reference stress-strain curve, representing the basic 


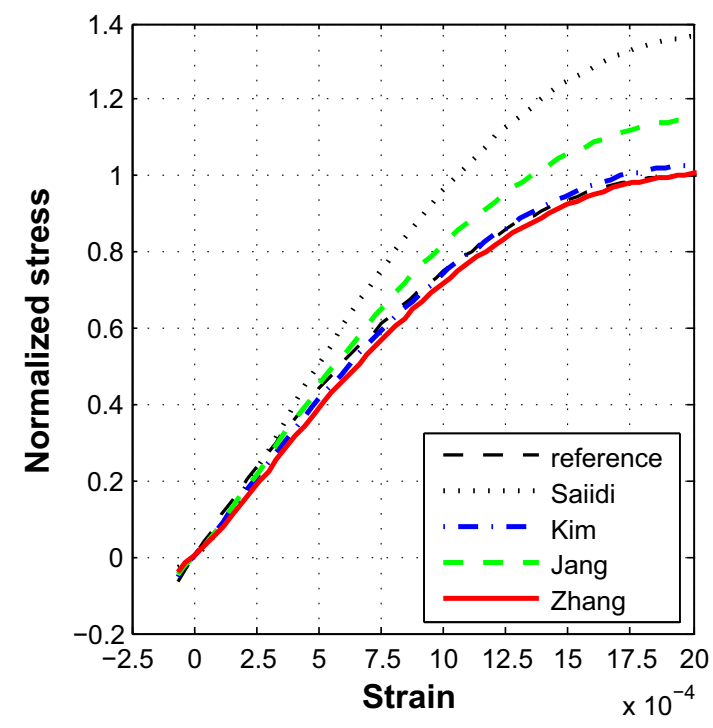

Fig. 19 Identified stress-strain relationships in pre-peak branch.

Hognestad parabola, Eq. 2 (or similarly Eq. 5 with $\varepsilon_{s h}$ equal to zero).

The identified concrete compressive strengths resulted in two cases (Kim et al. and Jang et al.) very similar to the concrete nominal strength obtained by testing concrete samples at 28 days. In the other two cases, the identified values are higher than the corresponding nominal values. This could be ascribed to the age of concretes at the time of dynamic testing greater than 28 days.

The identified values of parameter $\varepsilon_{s h}$ resulted in the range of $0.055 \times 10^{-3}-0.091 \times 10^{-3}$ (Table 5). These values are much smaller than those estimated based on the provision of fib Model Code (fib International Federation for Structural Concrete, Model code 2010) as:

$$
\varepsilon_{c s}\left(t, t_{s}\right)=\varepsilon_{c a s}(t)+\varepsilon_{c d s}\left(t, t_{s}\right)
$$

For instance, the final total shrinkage predicted by the $f i b$ Model Code for structural concretes in different atmospheric condition and with different notional sizes is in the range of $0.26 \times 10^{-3}-0.57 \times 10^{-3}$ and thus $3-10$ times bigger than those resulting from the identification. This result reflects the fact pointed out in par. 3.4 that micro-cracking produced by hindered shrinkage strains only affect the concrete where contraction is prevented. Thus, it happens around the steel rebars and close to the formworks and not on the entire concrete section as assumed in numerical simulations.

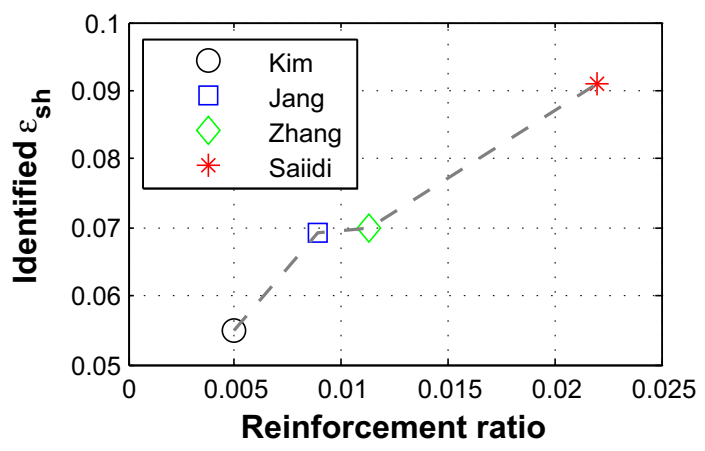

Fig. 20 Relationship between the identified parameter $\varepsilon_{s h}$ and beam reinforcement ratio.

The last parameter, the exponent $a$, assumed values in a limited range of 5015-7716 (Table 5). These high values identified by optimization procedure, produce fast transitions of stress-strain curves between unloaded condition and translated stress-strain curve of micro-cracked concrete. This means that micro-cracks are completely closed by the application of small compressive stress, letting the concrete behaves as though it is uncracked, but with increased strain values after the closure of the micro-cracks.

Looking at the results of experimental tests, some preliminary comments can be made on the prestressing level at which concrete softening becomes significant, although at the current state of research, it is not easy to define this value accurately since many factors, such as the eccentricity of prestressing force, the external bending moment, etc. affect concrete softening in different position of the beam cross section. In Table 6 the ratios between average compressive stresses and identified concrete strengths for the four experimental tests are reported. In the same table, the relevance of concrete softening in reducing frequencies of vibrations for increasing values of prestressing force inferred from Figs. 12, 14, 16 and 18 are indicated. For instance it can be noted that in tests by Saiidi et al. the rate of increase of the 1st frequency of vibration decreases as prestressing force increases, while it is almost constant in the tests carried out by Kim et al. (see also Fig. 1). It can be observed that generally concrete softening increases its relevance as the ratio between average compressive stress and concrete strength becomes higher.

A further interesting observation can be made on the data shown in Fig. 20 where for each experimental work the relationships between identified parameter $\varepsilon_{s h}$ and

Table 6 Concrete softening in four experimental tests.

\begin{tabular}{c|c|c|c|c}
\hline Experimental tests & $\sigma_{c, \text { mean }}$ & $f_{c, \text { iden }}$ & $\sigma_{c, \text { mean }} / f_{c, \text { iden }}$ & Compression softening \\
\hline \hline Saiidi et al. (1994) & $(\mathrm{MPa})$ & $(\mathrm{MPa})$ & 0.364 & Relevant \\
\hline Kim et al. (2010) & 10.1 & 27.8 & 0.039 & Absent \\
\hline Zhang and Li (2007) & 1.0 & 24.3 & 0.097 & Moderate \\
\hline Jang et al. (2010) & 4.17 & 43.1 & 0.165 & Moderate \\
\hline
\end{tabular}


reinforcement ratio of tested beams are plotted. An almost linear relationship between these two parameters with higher micro-cracking effects expected for higher reinforcement ratios can be observed.

Nevertheless, it must be pointed out that in real structures other aspects should be considered in order to identify prestress losses accurately. For instance, in pretensioned elements, the beam is subjected to a relevant variation of the prestressing force from a 0 value at each end of the beam to the full prestressing force at the end of the development lengths. In post-tensioned parabolic strand configurations, friction between tendons and ducts reduces the pretension force along the beam. Thus, in both cases a non-uniform prestress force is present along the beam and its variation should be considered in dynamic identification process.

\section{Conclusions}

In this work, several aspects that could influence the effect of prestress force on the dynamic behavior of prestressed reinforced concrete (PRC) beams have been analyzed. Whereas many references found in the literature state that prestressing force does not affect the frequencies of vibration, almost every experimental test carried out on PRC beams showed an increase in eigenfrequencies for increasing value of prestressing force. This trend is generally true for low values of prestressing level $(5-10 \%$ of the ultimate compression strength of the section) while for higher values of prestressing force, the rate of change of frequencies of vibration is reduced. For even higher prestressing force, the eigenfrequencies tend to decrease.

This overall behavior is a consequence of several features of concrete mechanics such as micro-cracking produced by hindered volume contraction, its nonlinear compressive stress-strain behavior with concrete softening and its low tensile strength. In particular the effect of the concrete microcracking has been proven to have a significant effect on the dynamic behaviour of PRC beams with varying prestressing forces.

Taking these features into account, inverse analysis has been carried out to identify the effective stress-strain relationship of concrete in several experimental works found in literature, expressed in terms of some unknown parameters. The identified parameters that model the influence of micro-cracking produced by concrete shrinkage are in good agreement with the expected values. Obtained results confirm that prestressing force level affects the dynamic behavior of PRC beams. Dynamic identification, therefore, can potentially be used to identify prestressing force level and consequently the prestress loss, provided that the complete concrete mechanics and the environmental effects, such as temperature and humidity, are taken into account appropriately (Breccolotti et al. 2004; Xia et al. 2006).

\section{Open Access}

This article is distributed under the terms of the Creative Commons Attribution 4.0 International License (http:// creativecommons.org/licenses/by/4.0/), which permits un restricted use, distribution, and reproduction in any medium, provided you give appropriate credit to the original author(s) and the source, provide a link to the Creative Commons license, and indicate if changes were made.

\section{References}

Bartoli, I., Nucera, C., Phillips, R., Salamone, S., Srivastava, A., Di Scalea, F., Coccia, S., \& Sikorsky, C. (2009). Stress monitoring in prestressing tendons for post-tensioned concrete structures by nonlinear ultrasonic guided waves. In Proceedings of the 7th international workshop on structural health monitoring, IWSHM 2009 (Vol. 2, pp. 2115-2122).

Bentur, A., \& Kovler, K. (2003). Evaluation of early age cracking characteristics in cementitious systems. Materials and Structures, 36, 183-190.

Breccolotti, M., Franceschini, G., \& Materazzi, A. (2004). Sensitivity of dynamic methods for damage detection in structural concrete bridges. Shock and Vibration, 11(3-4), 383-394.

Breccolotti, M., \& Materazzi, A. (2008). Identification of a nonlinear spring through the Fokker-Planck equation. Probabilistic Engineering Mechanics, 23(2-3), 146-153.

Breccolotti, M., \& Materazzi, A. (2015). Prestress losses and camber growth in wing-shaped structural members. PCI Journal, 60(1), 98-117.

Breccolotti, M., Materazzi, A., \& Venanzi, I. (2008). Identification of the nonlinear behaviour of a cracked RC beam through the statistical analysis of the dynamic response. Structural Control and Health Monitoring, 15(3), 416-435.

CEN European Committee for Standardization, EN 13791. (2007). Assessment of in-situ compressive strength in structures and precast concrete components. Brussels: CEN.

Chan, T., \& Yung, T. (2000). A theoretical study of force identification using prestressed concrete bridges. Engineering Structures, 22(11), 1529-1537.

Devalapura, R., \& Tadros, M. (1992). Stress-strain modeling of 270 ksi low-relaxation prestressing strands. PCI Journal, 37(2), 100-106.

Fafitis, A., \& Shah, S. (1985). Predictions of ultimate behavior of confined concrete columns subjected to large deformations. ACI Journal, 82(4), 423-433.

$f i b$ International Federation for Structural Concrete. (2010). Model code 2010, vols. 1 \& 2, final draft, bulletins 65 \& 55, fib, Lausanne.

Gao, X., Qu, G., \& Zhang, A. (2012). Influences of reinforcement on differential drying shrinkage of concrete. Journal Wuhan University of Technology, Materials Science Edition, 27(3), 576-580. 
Goto, Y. (1971). Cracks formed in concrete around deformed tension bars. Journal Proceedings, 68(4), 1305-1312.

Hamed, E., \& Frostig, Y. (2006). Natural frequencies of bonded and unbonded prestressed beams-prestress force effects. Journal of Sound and Vibration, 295(1-2), 28-39.

Hognestad, E. (1951). A study of combined bending and axial load in reinforced concrete members. University of Illinois Engineering Experiment Station, Bulletin Series No. 399, Bulletin No. 1.

Hop, T. (1991). The effect of degree of prestressing and age of concrete beams on frequency and damping of their free vibration. Materials and structures, 24(3), 210-220.

James, M. L., Smith, G. M., \& Lutes, L. D. (1964). Dynamic properties of reinforced and prestressed concrete structural components. ACI Journal Proceedings, 61(11), 1359-1382.

Jang, J.-B., Lee, H.-P., Hwang, K.-M., \& Song, Y.-C. (2010). Prediction of prestress force on grouted tendonds by experimental modal analysis. In Proceedings of the IMAC-XXVIII.

Jang, J., Lee, H., Hwang, K., \& Song, Y. (2010). A sensitivity analysis of the key parameters for the prediction of the prestress force on bonded tendons. Nuclear Engineering and Technology, 42(3), 319-328.

Kaklauskas, G., Gribniak, V., Bacinskas, D., \& Vainiunas, P. (2009). Shrinkage influence on tension stiffening in concrete members. Engineering Structures, 31(6), 1305-1312.

Kerr, A. D. (1976). On the dynamic response of a prestressed beam. Journal of Sound and Vibration, 49(4), 569-573.

Kim, J.-T., Park, J.-H., Hong, D.-S., \& Park, W.-S. (2010). Hybrid health monitoring of prestressed concrete girder bridges by sequential vibration-impedance approaches. Engineering Structures, 32(1), 115-128.

Kim, J.-T., Yun, C.-B., Ryu, Y.-S., \& Cho, H.-M. (2004). Identification of prestress-loss in PSC beams using modal information. Structural Engineering and Mechanics, 17(3-4), 467-482.

Kovler, K., \& Roussel, N. (2011). Properties of fresh and hardened concrete. Cement and Concrete Research, 41(7), 775-792.

Lan, C., Zhou, Z., \& Ou, J. (2012). Full-scale prestress loss monitoring of damaged rc structures using distributed optical fiber sensing technology. Sensors (Switzerland), 12(5), 5380-5394.

Law, S., \& Lu, Z. (2005). Time domain responses of a prestressed beam and prestress identification. Journal of Sound and Vibration, 288(4-5), 1011-1025.

Lu, Z., \& Law, S. (2006). Identification of prestress force from measured structural responses. Mechanical Systems and Signal Processing, 20(8), 2186-2199.

Maas, S., Znrbes, A., Waldmann, D., Waltering, M., Bungard, V., \& De Roeck, G. (2012). Damage assessment of concrete structures through dynamic testing methods. Part 1-Laboratory tests. Engineering Structures, 34, 351-362.

Madas, P., \& Elnashai, A. (1992). A new passive confinement model for the analysis of concrete structures subjected to cyclic and transient dynamic loading. Earthquake Engineering and Structural Dynamics, 21, 409-431.
Mander, J., Priestley, M., \& Park, R. (1988). Observed stressstrain behaviour of confined concrete. ASCE Journal of Structural Engineering, 114, 1827-1849.

Materazzi, A., Breccolotti, M., Ubertini, F., \& Venanzi, I. (2009). Experimental modal analysis for assessing prestress force in PC bridges: A sensitivity study, IOMAC 2009-3rd International Operational Modal Analysis Conference (pp. 585-594).

MathWorks, Matlab R2007a.

Miyamoto, A., Tei, K., Nakamura, H., \& Bull, J. (2000). Behavior of prestressed beam strengthened with external tendons. Journal of Structural Engineering, 126(9), 1033-1044.

Noh, M.-H., Seong, T.-R., Lee, J., \& Park, K.-S. (2015). Experimental investigation of dynamic behavior of prestressed girders with internal tendons. International Journal of Steel Structures, 15(2), 401-414.

Park, R., Priestley, M., \& Wayne, D. (1982). Ductility of square confined concrete columns. ASCE Journal of Structural Division, 108, 929-950.

Popovics, S. (1973). A numerical approach to the complete stress-strain curve of concrete. Cement and Concrete Research, 3(5), 583-599.

Saiidi, M., Douglas, B., \& Feng, S. (1994). Prestress force effect on vibration frequency of concrete bridges. Journal of Structural Engineering (United States), 120(7), 2233-2241.

Salawu, O. (1997). Detection of structural damage through changes in frequency: A review. Engineering Structures, 19(9), 718-723.

Sule, M., \& van Breugel, K. (2004). The effect of reinforcement on early-age cracking due to autogenous shrinkage and thermal effects. Cement and Concrete Composites, 26(5), 581-587.

Tanimura, M., Shimoyama, Y., Omori, H., \& Sato, R. (2003). Improvement of flexural behavior of reinforced high strength concrete members by reducing autogenous shrinkage, EAC'01: International RILEM Conference on Early Age Cracking in Cementitious Systems (pp. 343-353) .

Taucer, F., Spacone, E., Filippou, F.: A fiber beamcolumn element for seismic response analysis of reinforced concrete structures, Report EERC 91/17 (1991).

Vecchio, F. (1992). Finite element modeling of concrete expansion and confinement. ASCE Journal of Structural Engineering, 118(9), 2390-2406.

Xia, Y., Hao, H., Zanardo, G., \& Deeks, A. (2006). Long term vibration monitoring of an rc slab: Temperature and humidity effect. Engineering Structures, 28(3), 441-452.

Xiong, H.-X., \& Zhang, Y.-T. (2009). Theoretical analysis of natural frequency of externally prestressed concrete beam based on rigidity correction. Academic Journal of Xi'an Jiaotong University, 21(1), 31-35.

Zhang, Y., \& Li, R. (2007). Natural frequency of full-prestressed concrete beam. Transactions of Tianjin University, 13(5), 354-359. 